\title{
Por que é tão difícil avaliar a efetividade da interconsulta psiquiátrica?
}

Existem três categorias de pesquisas em interconsulta psiquiátrica: descrição de serviços, estudos clínicos e avaliação de resultados. ${ }^{1}$ Nos últimos dez anos, pôde-se observar o crescimento do número de estudos voltados para a avaliação de resultados, e, entre eles, aqueles cujo objetivo era fazer uma avaliação de custo-efetividade. ${ }^{2}$ Utiliza-se, geralmente, a análise de custos por meio de um único indicador, por exemplo, tempo de internação, habitualmente levando a resultados do tipo "custo-economizado" (cost saving), pretendendo atestar a qualidade do serviço ofertado. Outros estudos avaliam a melhoria psicopatológica decorrente do atendimento, cujo indicador é aferido pelas escalas de sintomas. ${ }^{3}$ Uma avaliação criteriosa desses trabalhos mostra falhas metodológicas importantes, como a escolha de instrumentos inadequados para medir alterações decorrentes do atendimento realizado e dificuldade de constituir um grupo-controle contemporâneo ao experimental. ${ }^{4}$

Será que a efetividade da intervenção dos serviços de interconsulta psiquiátrica se resumiria à diminuição de dias internados ou de sintomas psiquiátricos? Não seria o uso dessas medidas um artifício incorporado do modelo tradicional de avaliação hospitalar - o binômio morbidade/mortalidade - à avaliação desse tipo de serviço?

Caso se atentar para as características do objeto desse estudo, ver-se-á que ele comporta muito mais que esse binômio. $\mathrm{O}$ atendimento em interconsulta objetiva intervir não somente no paciente, mas também em conflitos psíquicos que podem encontrar-se exacerbados com o adoecer físico, a ansiedade dos familiares e a dificuldade de relacionamento entre equipe de saúde-paciente/família. Assim, parece existir um paradoxo entre o que se vivencia no trabalho clínico e o que tem sido objeto de pesquisas científicas nessa área.

Faz-se necessária uma redefinição do objeto de pesquisa, contemplando todos os fatores relacionados à efetividade dos serviços de interconsulta. Entende-se que esse objeto possui uma estrutura triangular, cujos vértices são paciente, família e

\section{Referência}

1. Botega NJ. Psiquiatria no hospital geral: histórico e tendências. In: Botega NJ, ed. Prática psiquiátrica no hospital geral: interconsulta e emergência. Porto Alegre: Artmed Editora; 2002. p. 15-30.

2. Udvarhelyi S, Colditz GA, Rai A, Epstein AM. Cost-effectiveness and cost-benefit anslysis in medical literature - Are the methods being used correctly? Ann Int Med 1992;116:238-44.

3. Carr VJ, Lewin TJ, Reid AL, Walton JM, Faehrmann C. An evaluation of the effectiveness of a consultation-liaison psychiatry service in general practice [see comments]. Aust N Z J Psychiatry 1997;31(5):714-25 equipe de saúde. Assim, devem-se medir não somente melhoria sintomatológica ou redução de custos hospitalares mas também o bem-estar subjetivo do paciente durante a internação, a melhoria de adesão ao tratamento, a sobrecarga emocional da família, os cuidados da equipe com o paciente e os benefícios de instrumentalização da equipe no sentido de reconhecer, elaborar e prevenir dificuldades associadas à tarefa assistencial em hospital geral.

O desenho utilizado para a investigação também dificulta a realização de estudos de avaliação nesse tipo de serviço. Se, por um lado, a natureza do atendimento impede a realização de um ensaio clínico verdadeiro, ${ }^{5}$ devido à impossibilidade de sortear aleatoriamente o grupo experimental (pois sempre depende de demanda), por outro, os estudos que se aproximam de uma reprodução do funcionamento real do serviço (caso-controle) não foram capazes, até o momento, de comprovar a efetividade observada na clínica. ${ }^{3}$

Somente quando equacionada a dificuldade do método de investigação e a utilização de instrumentos que atuem como indicadores de efetividade do objeto completo da interconsulta psiquiátrica, poder-se-á realizar uma avaliação de efetividade que seja fiel ao objeto de estudo desse trabalho.

Vanessa de A Citero

Departamento de Psiquiatria da Unifesp/EPM

Paola Bruno de A Andreoli

Unidade de Saúde Mental do Hospital Israelita Albert

Einstein

Departamento de Psiquiatria da Unifesp/EPM

Luiz Antonio Nogueira-Martins

Departamento de Psiquiatria da Unifesp/EPM

Sérgio B Andreoli

Departamento de Psiquiatria Unifesp/EPM e Núcleo de

Estatística e Metodologia Aplicadas (NEMAP)

4. Strain JJ, Hammer JS, Fulop G. APM task force on psychosocial interventions in the general hospital inpatient setting: a review of cost-offset studies. Psychosomatics 1994;35:253-62.

5. Hengeveld MW, Ancion FAJM, Rooijmans HGM. Psychiatric consultations with depressed medical inpatients: a randomized controlled cost-effectiveness study. Intl $\mathrm{J}$ Psychiatry Med 1988;18(1):33-43 